\title{
DIE GEBRUIK VAN TERRORISME AS 'N INTERNASIONALE POLITIEKE BEDINGINGSINSTRUMENT:
}

\author{
O/LT A. W. L. ROOTHMAN*
}

\begin{abstract}
Terrorism can no longer be seen as a limited form of behaviour, but as an escalating form of behaviour of which the ultimate result may prove fatal for the international community. It would appear that in some instances it may be easier to fight a war than to fight terrorism. One can only wonder to what extremes it may yet develop, especially in the nuclear era. This article is a detailed discussion of terrorism as an instrument for international political bargaining.
\end{abstract}

Die term 'terrorisme' is welbekend aan alle Suid-Afrikaners, trouens aan die hele wêreld. Terrorisme is aan die orde van die dag, dit het die onbekende en onsigbare vyand van almal geword. Niemand kan met sekerheid sê wanneer en waar hulle gaan toeslaan nie, dit is ook nie altyd duidelik wat die rede vir hul optrede is nie.

Daar bestaan vandag 'n hele aantal variasies van terrorisme, sommige is militêr ge-orienteerd terwyl andere weer 'n kriminele patroon van optrede toon. Ondanks hierdie verskille bly hulle wesenlik dieselfde, aangesien hulle die rol van 'verskrikkers' vervul.

Daar sal in die res van hierdie artikel gepoog word om onderskeidings tussen terroriste en ander groepe, asook interne verskille en werkswyses aan te toon.

\section{Wat is terrorisme?}

Voordat 'n mens na die rol van terrorisme as politieke bedingingsinstrument kyk, is dit nodig om die begrip 'terrorisme' te verklaar. Dit is geen eenvoudige taak nie, omdat daar 'n hele aantal betekenisse aan die term gekoppel word. Daar bestaan vandag nog verskil tussen deskundiges oor wanneer 'n optrede as terrorisme bestempel kan word. Daar word dikwels na terroriste verwys as vryheidsvegters en guerillas, maar hoe word hierdie terme aan mekaar gekoppel?

Volgens 'A Dictionary of Social Sciences' is terrorisme die sistematiese geweld wat daarop gemik is om die staatsgesag te ondermyn en vrees in te boesem ${ }^{1}$. Hierdie is 'n baie duidelike en eenvoudige verklaring. As ons na Suid-Afrika se verlede kyk, sowat 20 jaar gelede, kan ons die aanslag van destyds dadelik as terrorisme klassifiseer. Die Rivonia-gebeure was gemik op die ondermyning van die regering asook vrees- aanjaging. Reading gee ook ander definisies van terrorisme, wat vir doeleindes van hierdie studie nie juis relevant is nie. So meld hy ook dat terrorisme 'n regime van vrees of 'n beleg van vrees kan wees. Dit kan ook die eksterne intimidasie van nie-lede van 'n party wees of die interne intimidasie deur lede van 'n party.

Terrorisme word ook beskou as die rewolusionêre metode waardeur die bevolking oorgehaal word om samewerking te gee aan rewolusionêres deur die proses van vreesaanjaging. So kan ryk persone beweeg word om geldelike bydraes te lewer aan die rewolusionêres, wanneer daar dreigemente teen hul lewens gelewer word of dié van hul families. Arm mense kan weer verplig word om huisvesting en kos te verskaf of ten minste inligting van die polisie of militêre te weerhou. In die operasionele gebied en ook in Rhodesië is dit die patroon wat gevolg word. Daar word op groot skaal van die landelike bevolking gebruik gemaak om hulp te verleen.

\section{Die verband tussen terrorisme, guerillas en rewolusionêres}

Daar bestaan dikwels verwarring oor die terme terrorisme, guerillas en rewolusionêres. Soms word die indruk geskep dat hierdie benamings net verskillende terme is, of soms wil dit voorkom asof dit drie verskillende dinge is met geen verband nie. Die waarheid is dat die drie terme in 'n mate oorvleuel. Terroriste kan dus ' $n$ vleuel van 'n rewolusionêre groep wees, 'n rewolusionêre groep kan ook van guerilla-oorlogvoering gebruik maak, wat op sy beurt weer terrorisme as faksie kan gebruik. Heel dikwels kan elkeen van die drie groepe optree sonder dat daar enige verband bestaan.

Die term guerilla is afkomstig van die Spaanse woord 'guera' wat 'klein oorlog' beteken². 
Guerilla-oorlogvoering verwys dus na 'n stel beginsels en taktieke wat gevolg word in 'n veldtog. Guerillaoorlogvoering moet nie net as 'n militêre aangeleentheid gesien word nie, daar moet ook na die politieke dimensie gekyk word. Wanneer dit in politieke dimensie gesien word kan die verband met terrorisme makliker bespeur word, indien daar wel 'n verband is.

Wilkinson toon egter ' $n$ paar verskille aan tussen terroriste en guerillas ${ }^{3}$. Guerillas kan met klein getalle veg en met onvoldoende wapens, maar soms, en dit gebeur heel dikwels, veg hulle volgens die reëls van 'n oorlog. So sal hulle persone krygsgevange neem en uitruil en ook die regte van persone in nie-vegtende hoedanigheid eerbiedig.

Terroriste ken egter geen perke nie en maak dikwels gebruik van grootskaalse sluipmoorde, die verwekking van 'algemene vrees' by die burgerlike bevolking, en gaan selfs sovêr om onskuldige buitelanders te vermoor wat die land van die rewolusionêres besoek het. 'n Paar jaar gelede was dit die geval toe buitelandse toeriste by die Victoria Falls in Rhodesië deur terroriste om die lewe gebring is.

Dit is dus duidelik dat alhoewel guerillas dikwels terroriste gebruik of deur terroriste gesteun word, terrorisme nie met guerilla oorlog in die algemeen vergelyk kan word nie. Terrorisme is 'n spesifieke manier of proses van geweld met ten minste drie basiese elemente:

1. die terroristiese doelwitte van die persone wat dit bedryf;

2. die modus operandi wat hulle openbaar en spesifiek die vorms van geweld wat hulle gebruik om die doelwitte te bereik;

3. die sielkundige effek van terroristiese geweld op die slagoffers en toeskouers.

Dikwels is daar geen doelwitte te onderskei nie, altans so kom dit voor, maar by verdere ontleding sal dit tog blyk dat daar een of ander faktor van politieke aard is wat aanleiding gee tot die optrede.

\section{Die verskille tussen (1) vrees en terro- risme en (2) politieke terrorisme en ander vorme van terrorisme}

Uitbreidings van grootskaalse massageweld soos aangetref in oorloë en rewolusies bring onvermydelik ook toestande van vrees teweeg by die bevolking. Hierdie soort vreesaanjaging moet egter onderskei word van sistematiese regimes van geweld, bv dié soos aangetref in die Franse en Russiese rewolusies. Dit is daarom nuttig om te onderskei tussen die toevallige geweld wat massageweld teweegbring en sistematiese terrorisme van groepe of regimes van vrees, wat van vreesaanjaging gebruik maak as 'n werkswyse van sielkundige oorlogvoering en wat dit eksplisiet beplan.

Terrorisme kan in sekere gevalle nie-polities van aard wees. Misdadigers het al dikwels van terrorisme gebruik gemaak om lospryse te verkry of ander vorme van privaatgewin. Misdadigers vind dat samewerking met terroriste hul soms goed te pas kom om die polisie te verwar; die terroriste maak weer gebruik van die professionele dienste van die misdadigers, bv die sluipmoordaanvalle en die plant van bomme.

Psigopate het ook al dikwels van terrorisme gebruik gemaak sonder dat hulle weet hoekom hulle dit doen. Sekere verveelde, sadistiese en swaksinnige persone mag terrorisme gebruik om hul frustrasies uit te druk asook hul haat deur dade van simboliese protes en weerwraak teen die samelewing.

Dit is egter in politieke terrorisme waar die belangstelling hier lê. Politieke terrorisme kom neer op die doelbewuste intimidasie van die bevolking. Dit is dinge soos die sistematiese doodmaak van mense en afbreking van orde om sodoende individue, groepe en regerings te oorreed om gehoor te gee aan die terroriste se eise. Dit is een van die oudste tegnieke van sielkundige oorlogvoering. 'n Primêre doelwit vir terrorisasie word uitgesoek, 'n boodskap kan oorgedra word en die geloofwaardigheid by die slagoffer word geskep om hom te oortuig dat daar uitvoering aan die dreigement gegee sal word. Die slagoffers van die werklike optrede van die terroriste mag dalk nie hul primêre doelwit wees nie. Die klein hoeveelheid geweld kan uitermatige gevolge hê op die omstanders. Die ou Chinese gesegde sê immers 'Kill one, frighten ten thousand'.

Individue en groepe moet slegs as terroriste beskou word op die basis van voldoende historiese getuienis dat hulle verantwoordelik gehou kan word vir 'n veldtog van doelbewuste terrorisasie. Hierdie getuienis is egter somtyds moeilik verkrygbaar en hierdie 'terroris' kan ook dikwels tot ander aksies en metodes van geweld oorgaan, anders as terrorisasie. 
Soos reeds aangetoon kan terroriste in die begin stadia van rewolusies voorkom wanneer slegs klein faksies in terrorisme spesialiseer. Om dus te sê dat 'terroris' net 'n benaming vir 'n vryheidsvegter is, is om eenvoudig die oë te sluit vir lelike gebiede van historiese en psigologiese werklikheid.

\section{Klassifikasie van terrorisme}

Wanneer ons na alle vorme van terrorisme in die geheel kyk, kan daar hoofsaaklik drie indelings gemaak word, nl:

1. onderdrukkende terrorisme, dit word meestal deur state gebruik om sekere groepe of individue te beperk;

2. sub-rewolusionêre terrorisme, wat vir 'n verskeidenheid van redes aangewend word; en

3. rewolusionêre terrorisme, wat gemoeid is met verandering in die politieke stelsel. Hiervan is net twee groepe vir hierdie studie relevant.

\section{Sub-rewolusionêre terrorisme}

Doelwitte: Politieke motiewe gemik op fundamentele rewolusionêre verandering bv om regerings te dwing om veranderings in sy beleid of regstelsel aan te bring, die verwydering of straf van beamptes en politieke konflik met mededingende groepe.

Kenmerke: Word meestal gebruik deur klein groepies alhoewel individue alleen mag optree, dit is hoogs onvoorspelbaar en dikwels is dit moeilik onderskeibaar van psigopatologiese en kriminele geweld.

\section{Rewolusionêre terrorisme}

Doelwitte: Rewolusie of taktiese rewolusionêre doelwitte.

Kenmerke: Alhoewel dit 'n groepverskynsel is, sal dit hoe klein die groep ook mag wees, oor leierskap en ideologie beskik. Dit sal ook alternatiewe institusionele strukture ontwerp. Die organisasie van geweld en terrorisme word gewoonlik onderneem deur spesiale para-militêre eenhede binne die rewolusionêre beweging.

\section{Daar kan ook seker sub-tipes onderskei word nl.:}

1. Organisasies van suiwer geweld;

2. Rewolusionêre en nasionale bevrydingspartye en bewegings waar vreesaanjaging as addisionele instrument gebruik word;

3. Guerilla terrorisme;

4. Rewolusionêre regime van terreur;
5. Propaganda van die daad; en

6. Internasionale terrorisme.

In baie gevalle sal ' $n$ terroriste-beweging egter ' $n$ vermenging van twee of meer van hierdie sub-tipes wees. 'n Beweging kan suiwer geweld toepas en internasionaal optree.

\section{Kenmerke van terroristiese geweld}

1. Terroriste tree op sonder onderskeid. Alhoewel terroriste dikwels daarop aanspraak maak dat hulle kieskeurig en rasioneel te werk gaan, ook dat hulle die presiese gevolge van hul dade kan voorspel, is dit nie in die praktyk so nie. In baie gevalle sal onskuldige persone ook onder hul dade moet ly en sal die gevolge van die dade ernstiger wees as wat beplan is. Geen persoon kan seker wees dat hy nie die volgende slagoffer gaan wees nie.

2. Terrorisme is 'n onvoorspelbare verskynsel, beide in die verstand van die slagoffer asook wat betref die gevolge op die omstanders. Omdat vrees 'n subjektiewe ervaring is, asook die feit dat mense verskillend reageer, is daar geen waarheid in die stelling dat terrorisme in staat is om die gevolge van hul dade op.die menslike gedrag te voorspel nie. Veral met media soos TV kan die gevolge groter wees as wat beplan is. Die spreuk kan vandag lui: 'Kill one, frighten ten million'.

3. Terrorisme erken geen oorlogsreëls of ooreenkomste nie. Dit weier om te onderskei tussen vegtendes en nie-vegtendes. Dit erken ook geen humanitêre toegewings aan gevangenes of gewondes nie. 'n Baie goeie voorbeeld hiervan is die aanval op die oorlewendes van die lugramp in Rhodesië. Alle lewens, insluitend dié van vroue en kinders word as offers vir die bereiking van die doel beskou. Geen persoon is onskuldig nie. Selfs die pelgrims van Puerto Rico is destyds nie ontsien met die aanval op die lughawe Lod deur die Japannese Rooi Leër nie. Soos Andreski meld is terrorisme ' $n$ tirannie wat geen rede in aanmerking neem nie. ${ }^{4}$.

4. Terroriste verwerp alle morele beperkings. Dit blyk veral uit hul barbaarse gruweldade asook die wapens wat gebruik word. In party gevalle het die IRL bornme laat ontplof wat met moere en koeëllaers gevul was om sodoende die maksimum aantal persone te dood of te beseer. 
5. Polities-gemotiveerde terrorisme word gewoonlik geregverdig op die volgende gronde:

a. enige handeling is geregverdig om die doelwit te bereik;

b. enige eksterne geweld is voordelig ongeag die gevolge;

c. terrorisme het al in die verlede geslaag en is die beste werkswyse om sukses te verseker;

d. die moraliteit van terroriste is gebaseer op " $n$ oog vir ' $n$ oog en 'n tand vir ' $n$ tand';

e. die teorie dat groter treurspel die land sal tref indien daar nie teen die vyande opgetree word nie, sodoende word 'n 'kleiner treurspel' geregverdig.

Volgens bogenoemde is dit duidelik dat terrorisme 'n evaluatiewe konsep is, dit is slegs betekenisvol om sekere gedrag as terrorisme te beskou indien ons opvattings van die samelewing die idees van vreedsame orde, vry van geweld en vrees insluit. As ons geweld in dieselfde lig sien as Sartre, as positief en verkieslik weens die vryheidskonsep, sal ons terrorisme nie as 'n sosiale en politieke probleem sien nie.

\section{Oorgawes aan terroriste}

Die teorie van terrorisme as politieke wapen is gebaseer op ' $n$ aantal aannames ivm die menslike gedrag. Hierdie aannames is egter vals of dit is nog nie bewys nie:

1. Dat mense wat 'n bedreiging van hul lewens ervaar meestal sal oorgee aan hul bedreigers en ook sodoende sal afstand doen van hul beginsels en waardes en sodoende hulself red;

2. dat terrorisme onvermydelik lei tot die terrorisasie van die teikens of slagoffers;

3. dat persone na 'n tydperk van blootstelling aan langdurige intimidasie sal ingee en hulself volkome sal onderwerp aan hul vervolgers.

Daar is hier 'n duidelike ooreenstemming met die teorie dat enige persoon ' $n$ finale breekpunt het wanneer hy geen marteling meer kan verdra nie. Die geskiedenis het egter getoon dat marteling nie altyd doeltreffend op alle persone toegepas kan word nie, party mense het 'n groter weerstandsvermoë en sal inligting weerhou ten spyte van volgehoue marteling.

\section{Kort termyn doelwitte van politieke terrorisme}

Een van die grootste ideale van 'n terroristegroep is om soveel moontlik publisiteit vir die groep en sy ideologie te verkry. Daar ontstaan 'n soort kompetisie om die voorblad van koerante te haal. 'n Belangrike aspek wat hier in gedagte gehou moet word, is die feit dat koerante deur die onderskeie regerings verbied kan word. Om hierdie rede sal terroriste wat teen 'n bepaaide regering werk hul toevlug tot buitelandse koerante neem.

'n Ander algemene doelwit is om soveel as moontlik volgelinge te trek en simpatie vir die saak te wen. Terrorisme kan gebruik word om 'n politieke krisis te verander in 'n gewapende stryd tussen die mense en die militêre magte. Dit kan ook daartoe bydra dat die regerings- en veiligheidsmagte oorreageer en sodoende kan die mense beweeg word om hul steun aan die terroriste te gee wat kan optree as 'n selfverdedigingsorganisasie.

Terrorisme word dikwels gebruik om intergemeenskaplike verhoudings te polariseer en alle versoenende elemente te vernietig. Dit was die geval in lerland, Ciprus en Algerië. Sommige kort-termyn taktiese doelwitte is 'n funksie van die terroriste-groep in die stryd om selfbehoud en lewensnoodsaaklike bronne te verkry bv. die gebruik van terreur om lospryse en wapens te bekom, en ander terroriste vrygestel te kry, om gevaarlike opponente te vernietig en om alle informante te straf en absolute geheimhouding en onderhorigheid te verseker.

\section{Wie, hoe en hoekom?}

Terroriste, sonder enige uitsonderings maak gewoonlik daarop aanspraak dat hulle namens die werkersklas veg. Wat egter snaaks is, is dat hulle in so baie gevalle deur universiteitstudente, gegradueerdes en die seuns en dogters van invloedrykes gelei word. Hulle rekruteer meestal onder die werkersklas en lê hulle veral toe op heterogene gemeenskappe en gekleurde gemeenskappe. ' $n$ Voorbeeld hiervan is die Simbionese Bevrydingsleër in Kalifornië wat Patty Hearst in 1974 ontvoer het. Baie van die lede is egter ook persone uit agterlike gebiede of mense met 'n kriminele agtergrond, persone wat uitgeworpenes is en geen ander toevlug het nie. Terroriste rekrute vanaf plase is omtrent onbekend.

Meestal begin werwing van terroriste by ideologiese indoktrinasie. Die mense word oortuig dat die terroriste in belang van die werkersklas optree, ongeag die verwerping van die gedagtes deur baie aanhoorders. Die terroriste-aanhangers 
glo dat hulle beter as ander weet. Hulle probeer hulself vorm volgens die model van ander rewolusionêres soos Lenin en Marx. Sommige glo dat hulle die beste bydrae tot die saak kan lewer indien hulle as martelaars optree.

\section{Werkswyse}

Terroriste-groepe het almal hul eie werkswyse. Sommige groepe sal net tot enkele metodes beperk bly terwyl ander groepe 'n kombinasie van optredes sal gebruik.

Ontvoering, sluipmoorde, afpersing is van die gewildste metodes van optrede onder terroriste. Die eensaamste en mees gevreesde oomblikke van diplomate, beamptes en sakemanne is wanneer hulle in aanraking kom met die bedreiging van ontvoering of sluipmoord. Dit was eers ongeveer in 1968 dat ontvoerings gebruik is vir politieke afpersings. Dit het in Guatamala begin en later na Brasilië, die Dominikaanse Republiek, Argentinië, en Uruguay versprei. Die Franse ondersteuners van afskeiding het in Kanada van die idee gebruik begin maak en in 1970 het dit ook na Turkye, Spanje Haïti en Mexico versprei.

Intussen het die Palestyne hul skakings begin kombineer met ontvoerings en afpersings. In lerland was daar ook 'n paar ontvoerings maar 'n ander patroon is gevolg. In 1974 is Patty Hearst ontvoer en was daar ook 'n mislukte poging om Prinses Ann te ontvoer.

In Latyns-Amerika het 'n ander vorm van ontvoering ontstaan, $\mathrm{nl}$. diplomatieke ontvoerings en aanvalle. Dit is deur Latyns-Amerikaanse rewolusionêre bewegings ontwikkel as ' $n$ bedreiging vir internasionale orde. Dit versteur normale diplomatieke verhoudings en verskaf aan die terroriste 'n kragtige wapen van publisiteit en politieke afpersings. Dit blyk gewild te wees onder alle terroriste-groepe. Dit is nie moeilik om die rede vir die gewildheid te vind nie. Statistieke het bewys dat ontvoering die enkele mees doeltreffende terroristiese metode geword het om lospryse te verkry en gevangenes vrygelaat te kry. Die beloning is hoog maar die risiko besonder laag. Navorsing het getoon dat in die meeste lande die ontvoerders 'n $80 \%$ kans het om vry te spring en te ontvlug.

Skakings is eers in $1958-1959$ as 'n politieke instrument gebruik toe Fidel Castro se broer, Raoul, begin het met skakings van vliegtuie na Kuba. Dit is gevolg deur ' $n$ hele aantal skakings

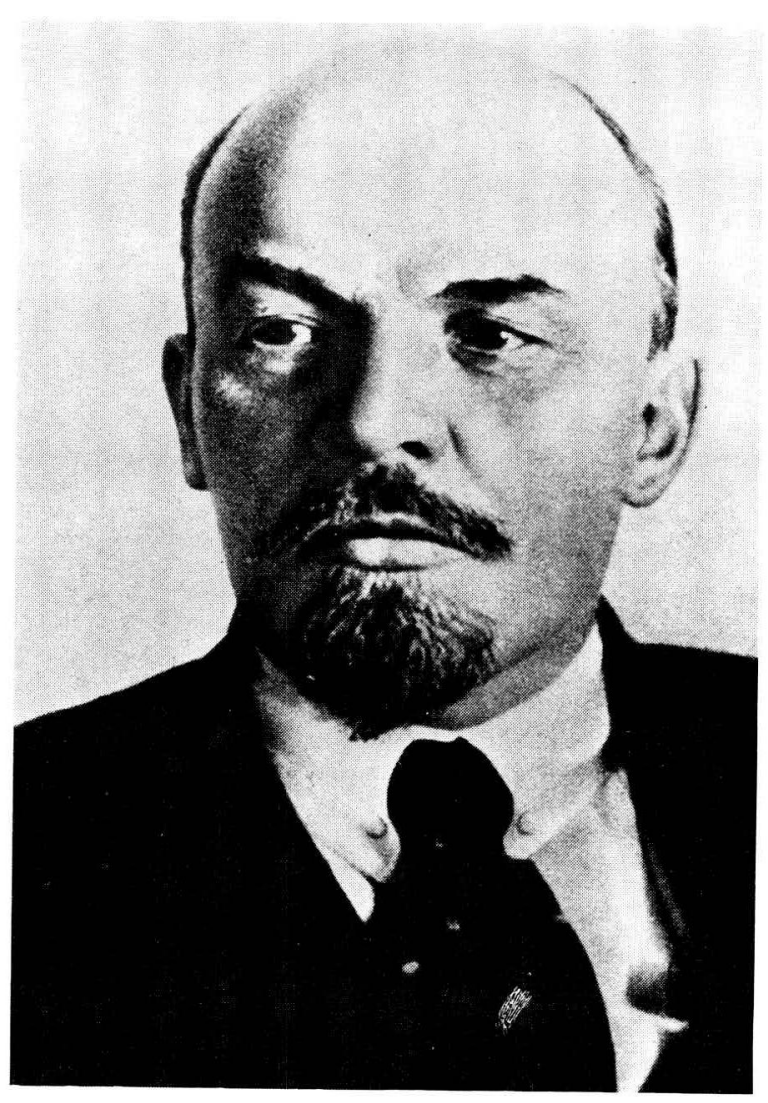

Terroriste en Terroriste-aanhangers probeer hulself vorm volgens die model van ander rewolusionêres soos Lenin en Marx.

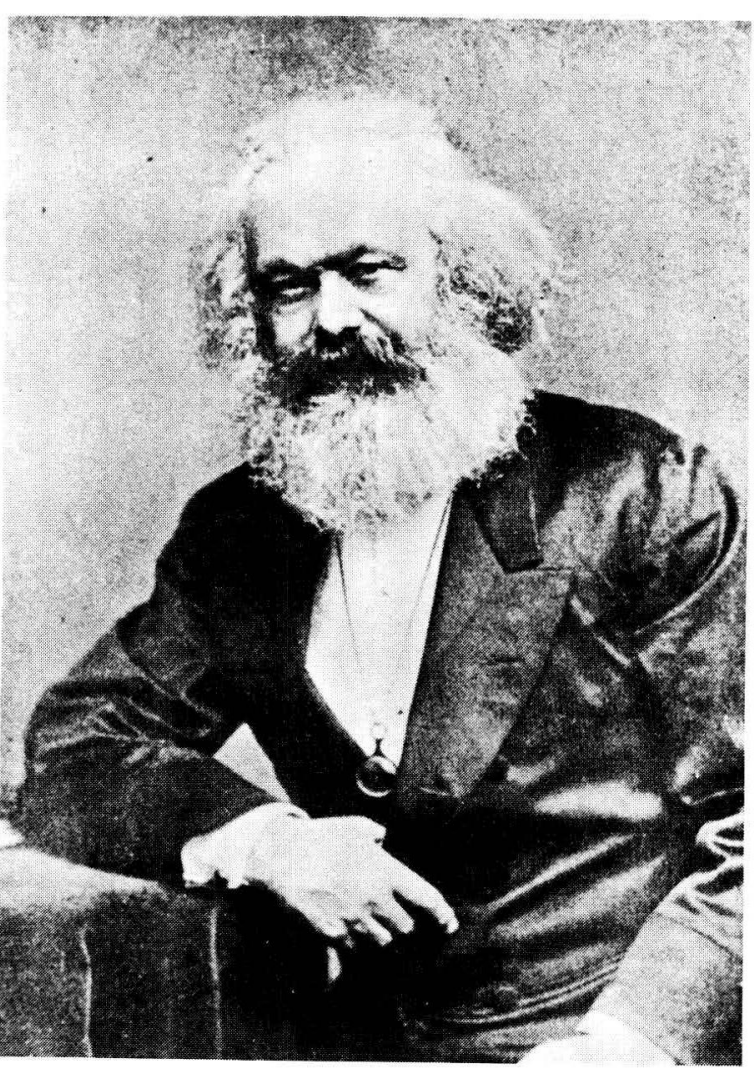


van vliegtuie na en van Kuba en Amerika. In 1968 het dit skielik 'n Wêreldepidemie geword. In daardie jaar was daar 38 skakings van vliegtuie waarvan 32 na Kuba was.

Die effek van skakings is baie groot. ' $n$ Mens kan nouliks begryp onder watter spanning die bemanning en passasiers van 'n vliegtuig moet verkeer met die horde van pistole, handgranate en ander plofstowwe om hulle. Vir rewolusionêre groepe en nasionale bevrydingsbewegings is dié vorm van terrorisme ideaal.

Dit is bewys dat vliegtuigskakings een van die mees doeltreffende maniere blyk te wees om politieke oogmerke te bevorder. Vliegtuigskakings mag ook 'n taktiese noodsaaklikheid word vir die suksesvolle bereiking van sekere langtermyn doelstellinge. Dit was die geval met Carlos en sy bondgenote in die massa skaking van OPEC ministers in 1975. Selfs nie die mees gesofisitikeerde internasionale vervoerstelsel is immuun teen terroriste-aanvalle nie. Dit is genoeg om enige vyand of opponent van terrorisme met vrees te vervul. Dit bly dan ook een van die doeltreffendste wyses van optrede van terroriste.

\section{Internasionale terroriste}

Hierdie internasionale terroriste-groepe word meestal gevorm deur persone wat gefrustreerd is omdat hulle nie rewolusionêre verandering binne hul eie lande kan teweegbring nie. Hulle glo dat interne bewegings nie slaag nie vanweë die feit dat die meeste persone nie ' $n$ versteuring in hul leefwyse wil hê deur rewolusionêre optrede nie. Daarom poog hulle om die gemeenskap in so 'n toestand van chaos te bring dat die mense sal ophou glo dat die huidige stelsel ordelike lewenswyse kan verseker. Hulle sal dan die filosofie van 'Situationism' ondersteun.

Die mees ekstreme faksie van hierdie groep glo dat hierdie chaos internasionaal moet wees. Vanweë twee redes:
1. omdat 'n buurstaat maklik andersins sal kan ingryp en deur die mense verwelkom word; en

2. dat insinking in een land dan vinnig sal versnel en sal uitbrei na ander lande en hul dus nie tot mekaar se redding sal kan kom nie. Op hierdie wyse sal verandering dan makliker veroorsaak kan word.

\section{Gevolgtrekking}

Uit al die bostaande gegewens blyk dit duidelik dat terrorisme vandag 'n belangrike politieke bedingingsinstrument geword het. In sommige gevalle sal dit makliker wees om 'n oorlog te veg as om terrorisme te beveg. Die verskynsel neem steeds toe, daar is amper nie 'n wêrelddeel wat nie geteister word nie en mens kan maar net wonder tot watter uiterstes hulle nog sal gaan, veral in die Kernera. Gaan terroriste nie dalk die plek van state inneem in konflikte nie? Dit is 'n moontlikheid wat nie buite rekening gelaat kan word nie. Ons sal terrorisme dus nie net moet sien as beperkte optrede nie, maar as ' $n$ moontlik eskalerende optrede waarvan die uiteinde fataal kan wees vir die internasionale gemeenskap.

* O/Lt A. W. L. Roothman is verbonde aan Vlootkommandement Opleiding, Simonstad.

**Bostaande artikel het die derde beste punt behaal in die Militêre Opstelwedstryd van 1979 en word geplaas vanweë die aktualiteit van die onderwerp.

\section{Bibliografie}

Baylis, J. Booth, K. Garnett, J. Williams, P. Contemporary Strategy Theories and Policies, London 1975.

Clutterbuck, R. Guerillas and Terrorists, London 1977.

Clutterbuck, R. Living with Terrorism, London 1975.

Hyams, E. A Dictionary of Modern Revolution, London 1973.

Lacquer, W. Terrorism, London 1977.

Reading, H. F. A Dictionary of the Social Sciences, 1977

Wilkinson, P. Political Terrorism, London 1974.

Wilkinson, P. Terrorism and the Liberal State, London 1977.

\author{
Voetnote \\ 1. Reading, F. A Dictionary of the Social Sciences, p 217. \\ 2. Hyams, E. A Dictionary of Modern Revolution, p 275. \\ 3. Wilkinson, $\mathrm{P}$. Terrorism and the Liberal State, $\mathrm{p} 52$. \\ 4. Andreski, S. 'Terror', in A Dictionary of the Social Sciences.
}

